\title{
On the Pragmatic Functions of English Rhetoric in Public Speech: A Case Study of Emma Watson's HeForShe
}

\author{
Bin Yuan ${ }^{1}$ \\ ${ }^{1}$ Foreign Language Department, Chengdu Sport Institute, Chengdu, China \\ Correspondence: Bin Yuan, Foreign Language Department, Chengdu Sport Institute, No. 2 Tiyuan Road, \\ Chengdu, China. E-mail: wyuanbin@sina.com
}

\author{
Received: November 19, 2017 Accepted: February 17, 2018 Online Published: February 19, 2018 \\ doi: 10.5539/elt.v11n3p113 URL: http://doi.org/10.5539/elt.v11n3p113
}

\begin{abstract}
The current research is mainly conducted to explore the pragmatic functions of English rhetoric in public speech. To do this, methods of close reading and case studies are adopted. The research first reveals that the boom of public speech programs helps reexamine the art of utterance, during the delivery of which English rhetoric plays an indispensable role in shaping and expressing a speaker's opinions, and then, with Emma Watson's HeForShe as a case study, concludes the specific pragmatic functions of English rhetoric: parallelism helps strengthen opinions; irony shows dissatisfaction, disapproval or rejection; rhetorical questions invite no answers, but call for emphasis and sense of urgency; contrast describes difference(s) so as to show preference. Use of proper English rhetoric devices in public speaking as well as in daily life improves communicative effect and efficiency.
\end{abstract}

Keywords: public speech, English rhetoric, pragmatic functions, HeForShe

\section{Introduction}

In recent years, with the release of such popular public speech programs as TED, "Real Time with Bill Maher" and "The Tonight Show with Conan O'Brien", which are from various countries with various themes and distinctive oratory characteristics, people are increasingly aware of the importance of interpersonal skills and the art of public speaking in daily life. In fact, public speech is not a new attraction, but an old art and activity that stems from ancient Greece over 2000 years ago. Public speaking is commonly understood as formal, face-to-face speaking of a single person to a live audience, and usually the purpose of public speech is to inform, to persuade, to entertain or to share personal experience. Undoubtedly, if a speaker wants to inform, persuade, or entertain the audiences, he/she should employ special means of expression effectively, among which English rhetoric such as irony, repetition, metaphor, parallelism, contrast, rhetorical question and etc., works well. And then comes the critical question that the current research aims to answer: what are the pragmatic functions of English rhetoric in public speeches since the two disciplines of English rhetoric and Pragmatics are closely related. (Ziran, 2000, p. $38)$.

Public speech is actually rich in English rhetoric; in other words, the delivery of any public speech must necessarily involve certain types of rhetoric. Rhetoric is the art of using speech effectively (Brooks, 1979, p. 5). The research, based on the case study of Emma Watson's HeForShe, attempts to explore the pragmatic functions of English rhetoric in public speech, and analyze the effective use of English rhetoric so as to help us learn to make the audience better persuaded/informed/entertained and improve communicative efficiency in daily life.

\section{Literature Review}

Studies into English rhetoric remains a key issue in Second Language Learning/Acquisition, and a large scope of researches are conducted on English rhetoric at home and abroad. Comparatively, studies abroad is more comprehensive and desirable, and works on rhetoric/English rhetoric are diverse, which offer extensive theoretic and practical reference to studies of rhetoric at home. For instance, the studies and research of Kenneth Burke (a rhetorical theorist, philosopher, and poet, and many of his works are central to modern rhetorical theory), I. A. Richards (a literary critic and rhetorician, and his The Philosophy of Rhetoric is an important text in modern rhetorical theory), and Stephen Toulmin (a philosopher whose models of argumentation have had great influence on modern rhetorical theory) are all enlightening in the studies of English rhetoric in China.

Scholars at home (Feng, 1983; Gao, 1999; Xia, 2009; Yu, 2009; Hu, 2011; Fan, 2013, and etc.) also made 
abundant studies of English rhetoric, ranging from its definition, linguistic features, introduction of western theories of rhetoric, applications of rhetoric in certain language contexts, case studies of rhetoric in various writings (for example, advertising), to its relations with politics, literature and culture studies. But a survey of CNKI with key words of "English rhetoric" and "pragmatic functions" shows that in the last twenty years from 1997 to 2017 only 11 journal papers and dissertations are published on the pragmatic functions of English rhetoric, among which only 4 papers are written with a general overview of the pragmatic functions of some English rhetoric devices (for instance, metaphor, pun, euphemism, and etc.), and just two others are conducted in certain type of writings such as advertising, and writing class. Obviously, the existing studies of the pragmatic functions of English rhetoric from the perspective of public speech is rare.

\section{Methods}

The current research is conducted with a case study of Emma Watson's HeForShe, which is a popular and well-know public speech with a distinctive theme of gender equality as well as distinctive linguistic features of rhetoric, and which well serve and support the research. It is a speech by UN Women Goodwill Ambassador Emma Watson at a special event for the HeForShe campaign at United Nations Headquarters, New York, on September 20, 2014.

Accordingly, the paper first explores the relation between public speech and English rhetoric as well as the general pragmatic functions of English rhetoric; then a close reading of Emma Watson's HeForShe is made so as to find proper examples/samples to analyze the specific pragmatic functions of some rhetoric devices in the speech. Therefore, in terms of research methodology, close reading and case studies are employed in the paper so that a sound conclusion can be made. In this case studies, 4 English rhetoric devices (parallelism, rhetoric question, irony, and contrast) are selected with 5 examples/samples for the analysis.

\section{Discussion and Case Studies}

\subsection{Overview of Public Speech}

Public speech, a special form of speech, is a process during which a speaker shares his/her ideas formally with a live audience face-to-face in public.(Cuihua, 1983, p. 1) It is similar to "presenting"; (Burke, 1969, p. 43) however, the latter is more closely related to some commercial activities. Public speeches are made for various purposes, and as a result, they consist of various types: information type, persuasion type, entertainment type and incentive type. The origin of public speech can be traced back to ancient Greece around 2000 years ago; it has a long story involving human's intelligence of utterance.

A great public speech asks for high demand of verbal expression; in consequence, a good speaker should make good use of and well control his/her voice, stop, pitch and rhyme such as alliteration, end rhyme and homophones. Public speech is an effective tool of communication, and in order to decrease the distance with the audience and enhance the degree of persuasion, a speaker often chooses the first person or the second person to express his/her feelings and share his/her experiences. With the boom of economic globalization and the increase in interpersonal communication, people from all over the world start to attach great importance to the art of public speech. That explains why more and more speech programs are released at a rapid speed every year.

English rhetoric can be defined as an art of communication with words, or a choice of linguistic methods to express oneself better (Zhuanglin, 2011, p. 47). In this sense, rhetoric, as an art of utterance, is widely used not only in writing and literary works, but also in interpersonal communication. However, most of the existing studies concentrate on the exploration and analysis of the relationship between English rhetoric and certain types of writing or literary works, or case studies of specific English rhetoric, for example, pun or metaphor, in certain type of public speech (Lifang, 2009, p. 26). In fact, there are few studies that attempt to analyze the close connection between rhetoric and public speech. In addition, little attention has been paid to the theoretical and pragmatic significance of English rhetoric in public speech. Against this research background in China, this paper aims to, with the case study of Emma Watson's HeForShe, reveal the practical significance of English rhetoric in public speech by analyzing its pragmatic functions.

There are many kinds of English rhetoric devices, for example, irony, metaphor, repetition, pun, rhetorical question and etc,. English rhetoric is widely employed in different language situations for different purposes. To name just a few, metaphor is one of the most common rhetorical phenomenon, which can be used to express and identify meanings in different language forms and situations. From the view of the inner space of language system, metaphor is not only the symbol of literary language but also the universal feature of human language. Metaphors, according to Aristotle, have "qualities of the exotic and the fascinating." (Moran, 1996, p. 34 ). For instance, "Time is money", is a sentence with the English rhetoric of metaphor. Another example is repetition, 
which is the simple repeating of a word, or a phrase within a sentence in order to secure emphasis. It is such a common literary device that it has connotations of listing for effect and is used very commonly by famous poets. In this paper, focus is made on several common and frequently used English rhetoric devices in a case study of Emma Watson's HeForShe and analyze their pragmatic functions. The current research involves 4 English rhetoric devices: parallelism, rhetoric question, irony and contrast. The 4 rhetoric devices belong to 2 types: syntactical stylistic devices (parallelism and rhetoric question), lexical stylistic devices (irony and contrast). (Ronggui, 1992. p. 82).

\subsection{General Pragmatic Functions of English Rhetoric}

In western tradition, rhetoric is a very ancient discipline, and its history can be traced back to ancient Greece when public speech and eloquence is an indispensable component of government and democracy. It is well-known that Aristotle, who is considered the ancestor of western classical rhetoric, described the principles of the rhetorical system and defined rhetoric as an ability of observing the persuasion that is useful in any known situation(s). Cooper (1933) points out that Aristotle divided public speech into three forms: forensic, deliberative and epideictic. What's more, he thought that there were three ways of persuasion: logos, pathos and ethos.

Generally, Pragmatics is a subfield of linguistics and semioticsto, and studies the meaning of language used in specific situations. There are two important aspects in pragmatics: meaning and context. In other words, pragmatics studies how the transmission of meaning depends not only on structural and linguistic knowledge of the speaker and listener, but also on the context of the utterance (Ladusaw, 2017). According to Hu Zhuanglin (2011, p. 18), a Chinese expert in linguistic studies, pragmatics "deals with particular utterances in particular situations and is especially concerned with the various ways in which many social contexts of language performance can influence interpretation." It regards speech performance as simply as a social action, which is ruled by different kinds of social conventions. In this sense, conversation in daily life is the performance of the use of pragmatics, and most of time, we use it unconsciously. Language is a carrier of communication which we must use in our everyday life, and pragmatics focus on the practical usage of language communication. From a linguistic point of view, these various rhetoric devices are not just figures of speech, but the application of language, which means we need care more about the practicality and functions of language in daily communication. Pragmatic function is a concrete concept, and different rhetoric methods may have different or similar pragmatic functions, depending on specific situations, or contexts, in which those methods are used. Analyzing pragmatic functions of English rhetoric in public speech can help us know how English rhetoric works in public speeches; by studying pragmatic functions of public speech, we can learn to communicate more effectively and efficiently. Both pragmatics and rhetoric refer to the practical use of language for special purposes. English rhetoric is, in fact, a choice to make a sound decision of utterance or expression in specific situations, which is, actually, part of studies of pragmatics.

There are some general pragmatic functions of English rhetoric in public speech. The first is emphatic function. The timely use of some English rhetoric devices in a public speech, for instance, parallelism, repetition, or rhetorical question, can highlight the theme of a speech, strengthen the speaker's attitude, and better serve his/her purpose of delivering the speech. Public speech is an art of persuasion. In order to achieve the aim of persuasion, and to get the approval of the audiences, a speaker needs to consider the skill of using English rhetoric. Taking one sentence from a public speech given by American President J. F. Kennedy for example, "All this will not be finished in the first 100 days. Nor will it be finished in the first 1000 days, nor in the life of this administration, nor even perhaps in our lifetime on this planet." Clearly, this sentence conveys the feeling of being gradually strengthened from "100 days" to "1000 days", and then to "our lifetime", and J. F. Kennedy wants to tell his audience that they still have a long way to go to achieve their aims. Through using English rhetoric - parallelism, Kennedy emphasizes the theme of the speech and encourages people to work together and make progress together. The second common pragmatic function is to show politeness. English linguist Geoffrey Leech (1983) divides pragmatic discipline into interpersonal rhetoric and textual rhetoric, and suggests that politeness principle plays an important role in interpersonal rhetoric. Generally speaking, the more indirect/mild the language is, the more polite the speech is. Accordingly, such English rhetoric devices as euphemism and understatement are frequently employed in public speech to show the speaker's prudence and reservedness so that a better communicative effect can be secured.

\subsection{Case Studies of Emma's HeForShe}

\subsubsection{Emma Watson and Her HeForShe}

Emma Watson is a British actress, model, and activist, and in addition, she is also a feminist who was born in Paris on the $15^{\text {th }}$ April in 1990 and brought up in Oxfordshire where she attended the Dragon School; she was 
trained as an actress at the Oxford branch of Stagecoach Theatre Arts. She was chosen as one of the main characters in Harry Potter films, a popular film series, and after that, she acted the same character in the total 8 Harry Potter series in 10 years. In 2011, Emma chose to take further education at Brown University in America so that she can not only feel the scholarly atmosphere and study in a quiet environment but also learn language and art. She got her BA degree in 2014. And in the same year, she was appointed as UN Women Goodwill Ambassador and served as an advocate for HeForShe campaign. She delivered a powerful speech at a special event in New York to kick-start the HeforShe campaign, a dynamic solidarity movement for gender equality.

In 2014, the campaign HeForShe launched by Emma Watson has aroused widespread concern among the media and the public. AS UN Women Goodwill Ambassador, Emma Watson, in the 12-minute speech, advocates that men should be actively involved in promoting gender equality instead of staying out of the affair. Gender equality is also good for men. Gender is only criterion of dividing but not a sign of opposing each other. In this speech, Emma Watson encourages people, men and women, to revolt unfair treatment in gender. The aim of the speech is to engage men and boys as agents of change by encouraging them to take action against negative inequalities imposed on women and girls. This public speech is a launch ceremony of United Nations Global Initiative and the core topic of this activity is "Men, gender equality is your issue, too."

\subsubsection{Sample Analysis in HeForShe}

Sample 1: "Apparently, I am among the ranks of women whose expressions are seen as too strong, too aggressive, isolating, anti-men and unattractive."

In this sample, the five words "strong, aggressive, isolating, anti-men and unattractive" consist of the rhyme as parallelism. Parallelism, also known as parallel structure or parallel construction, is a balance within one or more sentences of similar phrases or clauses that have the same grammatical structure, or more than one words of similar structure. Parallelism is an expressive mean of English rhetoric, which can line up the same or similar structure, consistent tone, and sentences or sentence compositions with close meaning to strengthen the language in words and deepen the feelings. Generally, parallelism is made up of three or more than three relative contents and their relationship is paratactic or progressive. Tibbets, the author of Strategies of Rhetoric, believes it is very important to use parallelism in daily life. He said, "It's impossible to talk sensibly about anything, from cardboard boxes to democracy to why people buy certain automobiles without employing parallelism." (Jun, 2013 , p. 6). Parallelism always plays a significant role in public speech, because it can not only strengthen the rhyme so as to help express the speaker's view, but also help the speaker get closer to the audience to influence them efficiently. In this sample, the five words "strong, aggressive, isolating, anti-men and unattractive" are the label of feminism; however, all of these characteristics are given by men. For a large number of males, they discriminate against these women who think women should fight for their own equal rights and they try to suppress this kind of females into a group of people out of tune. They think women should stay at home to take care of kids and do housework instead of working outside. From these five words, we can see they are all derogatory terms, and Emma uses these adjectives in succession. Her purpose is to let people feel the delima of gender inequality in which nearly all women are actually caught. By using parallelism, Emma enhances the effect of her expression to make both women and men go along with her feelings. Beyond that, parallelism makes her utterance and tone stronger and her language more fluent. When we talk about the pragmatic functions of parallelism, we can not only enhance the momentum of the speech and highlight the content, but also make the utterance read up catchy and full of rhythm. In fact, in our daily life, we always make use of parallelism to make our expression more reasonable and well-founded; what's more, the paralleled sentence pattern can help the speaker express confidently and persuade others to acknowledge the theme the speaker want to express. In this case, parallelism successfully helps her emphasize the theme of the speech and well bridge Emma Watson with her audience by shaping and demonstrating her speech forcefully.

Sample 2: "Why is the word such an uncomfortable one?"

In this sample, "word" here refers to feminism. This is a rhetorical question, one of the most effective English rhetoric methods. Rhetorical question is an English rhetoric device which expresses certain meaning(s) in the form of doubt. Usually, a rhetorical question does not await certain answers, but contains implied answers itself. By using this rhetoric method, Emma successfully appeals to everyone to pay more attention to the issue of gender equality, and she aims to invite everyone to consider this question and its explicit answer. By doing so, the theme of the speech as well as her attitude towards gender equality is strengthened. Obviously, this pragmatic function of rhetorical question is also helpful in our daily life. It pushes the audience to think about the theme or issue on their own initiative, and makes everyone get involved in the speech. The speaker can use this rhetoric method to get extensive consensus, thus achieving expected audience responses. 
Sample 3: "If not me, who? If not now, when?"

It is the last part of the speech, and built with rhetorical questions and elliptical sentences. Rhetorical question is fairly common in public speech, and is used to heighten the effect of persuasion. These sentences are used at the end of the speech, with urgency suggested by the elliptical sentences, to appeal to every individual to take part in HeForShe to do something immediately for gender equality. In the first rhetorical sentence, "me" stands for every man and woman, not just the speaker of the speech. From the two rhetoric sentences, we can get the message that everyone should take the responsibility to fight for gender equality from now on. In other words, there is no need for the speaker to say: "Now, every individual needs to participate in the activity called HeForShe. Let's do it!" Undoubtedly, people will accept the former with rhetorical question because the form makes them feel they are part of the campaign, and after the speech, they are excited that they can do something for the world by their own wish. In this sense, this rhetorical question make a great difference in the speech to arouse the audience's awareness of their responsibilities.

Sample 4: "How can we affect change in the world when only half of it is invited or feel welcome to participate in the conversation?"

It is irony. Irony, in its broadest sense, is a rhetorical device in which what appears, on the surface, to be the case, differs radically from what is actually the case (Hongyun, 1999, p. 37). Irony has a positive function in permitting aggression to manifest itself in a less dangerous verbal form than by direct criticism (Booth, 1974). Linguists divide irony into two types. One is the use of positive expression to express negative meaning(s) and the other is the use of negative expression to express positive meaning(s). Sometimes, irony and rhetoric question are mixed together to strengthen the tone and make the theme clearer to the audience. In this case, Emma Watson expresses her worry about people's reluctance to participate in the activity. A lot of people (even some women themselves) are not concerned enough about gender equality and that is her aim to launch the speech to appeal to more people taking part in the activity. The decisive force of pushing the promotion of gender equality needs the joint efforts of men and women. Emma Watson uses irony to sound the alarm for everyone. Irony makes her speech more vivid and urgent.

Sample 5: "These rights I consider to be human rights, but I am one of the lucky ones."

Here an implied contrast is employed in this sample. Contrast is commonly used in literary creation as an effective means of expression. A contrast is made to describes the difference(s) between two or more entities. This means of English rhetoric is conductive to show the contradictions of things and to strengthen the artistic effect of the article/speech. With contrast, the images of things can be richer and help audience to realize the importance of the current situation; in other words, contrast pushes people to face the problem and solve the problem. In sample 6, Emma uses contrast to emphasize that there are few women in the world with gender equality, so we must actively participate in the campaign, and try our best to fight for gender equality. By making the contrast, she asks an implied question: how many women can get their equal rights with men even if the population of women in the world is large? The answer is few. As a result, this contrast is made between "one of the lucky ones" and the whole women group to emphasize the grim situation. In the future, there will be more women as lucky as Emma. By doing so, Emma succeeds in strengthening the theme of the speech-joint efforts to promote gender equality.

\section{Conclusion}

With the analysis of Emma Watson's UN speech HeForShe, the paper explores the pragmatic functions of four typical English rhetoric devices which are parallelism, rhetoric question, irony and contrast, and reveals the close relationship between English rhetoric and public speech. English rhetoric is an abstract term with concrete contents. To enhance the effect of public speech, a speaker always uses some English rhetoric devices to make his/her language more lively and artistic, and in other words, the basic pragmatic function of English rhetoric is to help people express themselves efficiently. Nowadays, there are more opportunities as well as stages for people to express themselves in public, for instance, TED, Ellen Show and some other TV programs, whether their purpose is to inform, persuade, entertain or just to share their opinions and experiences. As a result, the popularity of public speech leads to the boom of speech training classes because people have the need to express and convey their ideas efficiently. The purpose of the paper is to find out how English rhetoric works for the expression of public speech in order to make English rhetoric serve for people's daily communication and interpersonal relationships effectively.

Based on the current studies, the paper concludes that English rhetoric is not limited to theoretical aspects, but applied to people's daily life and interpersonal communication as well. Thus, English rhetoric can be used not only in literary creation, but also in the utterance of daily conversation with others. Taking the public speech 
HeForShe as a case study, the research also aims to suggest that people need to learn more methods of effective expression in their interpersonal communication, among which rhetorical devices are good choices. For instance, such rhetorical devices as repetition, and parallelism can help a speaker to emphasize his/her opinions and strengthen his/her attitude; euphemism can help make the speech mild and modest; irony shows dissatisfaction, disapproval and rejection sometimes; contrast shows preference or likes/dislikes; besides, rhetorical questions invite no answers, but calls for emphasis and the sense of urgency in some cases. In fact, English rhetoric is not just a tool in writing or literary works, but an art of expression in daily life; it helps express ideas effectively, and improve communicative efficiency greatly.

\section{Acknowledgments}

Sincere gratefulness goes to the authors of the references for their sparkling ideas to inspire the research, and finally the writing of the paper, my wife CHENG Zhenzhen for her encouragement, and my friend Li Hang for his recommendation and advice.

\section{References}

Brooks, W. (1979). Modern Rhetoric. Harcourt Brace Jovanorich, Inc.

Booth, W. C. (1974). A Rhetoric of Irony. Chicago\& London: University of Chicago Press.

Burke, K. (1969). A Rhetoric of Motives. Berkeley: University of California Press.

Cuihua, F. (1983). English Rhetoric. Beijing: The Commercial Press.

Cooper, L. (1933). The Rhetoric of Aristotle. Classical Philology, 390-404.

Hongyun, G. (1999). A Pragmatic Analysis of English Rhetoric. Shandong Foreign Languages Teaching, 36-38.

Jiajie, Y. (2009). A Discussion on the Pragmatics Function of Rhetoric. Journal of Nanchang Vocational \& Technical Techers' College, 87-90. https://doi.org/10.3969/j.issn.1007-3558.2009.01.023.

Jun, F. (2013). On the Pragmatic Rhetoric of Parallel. Sichuan International Studies University. Retrieved from $\mathrm{http} / / / \mathrm{www}$. wanfangdata.com.cn/details/detail.do?_type=degree\&id=XWC201311280000003216

Ladusaw, W. (2017). Meaning (Semantics and Pragmatics). Linguistic Society of America. Retrieved from www.linguisticsociety.org

Lifang, X. (2009). On Cohesive Function of Parallelism. China: Changsha University of Technology.

Leech, G. (1983). Principles of Pragmatics. London: Longman.

Moran, R. (1996). Artifice and persuasion: The work of metaphor in the rhetoric. In Essays on Aristotle's Rhetoric, ed. Amelie Oksenberg Rorty. Berkeley: University of California Press.

Ren, H. (1998). On the Application and Studies of English Rhetoric. Foreign Languages Research, 3-4.

Richards, I. A. (1936). The Philosophy of Rhetoric. New York and London: Oxford University Press. https://doi.org/10.1017/S0031819100069138

Ronggui, M. (1992). On Some Unsettled Problems about English Rhetoric. Foreign Language Education, 77-82.

Toulmin, S. E. (2003). The Uses of Argument. Cambridge: Cambridge University Press. https://doi.org/10.1017/CBO9780511840005

Zhuanglin, H. (2011). Linguistics. Beijing: Peking University.

Ziran, H. (2000). Enlightenment from Pragmatics on Rhetoric Studies. Journal of Jinan University, 38-44.

\section{Copyrights}

Copyright for this article is retained by the author(s), with first publication rights granted to the journal.

This is an open-access article distributed under the terms and conditions of the Creative Commons Attribution license (http://creativecommons.org/licenses/by/4.0/). 